\title{
19 Use of eGK number or KV number
}

Are the electronic health card (eGK) and health insurance number (KVNR) particularly items worthy of protection in terms of data protection?

- Under what conditions may the TTP collect/process these data, is an explicit consent (consent policy) necessary for this or can these items be processed as IDATs?

- Under what conditions may TTP use this data for matching (determination of a person's identity)? (ID with wide scope for merging data)

\subsection{General Information on the eGK and the KVNR}

Each health insurance fund issues an electronic health card (eCK) for each insured person, which serves as proof of entitlement to benefits within the scope of GKV-accredited medical care (proof of insurance) as well as billing with the service providers (Section 291 para. 1 S. 1, 2 SGB V). The health insurance number (KVNR) is printed on the electronic health card (Section 291 para 2 S. 1 Nr. 6 SGB V).

The KVNR is defined in Section 290 SGB V. It consists of an unchangeable part for the identification of the insured person and a changeable part which contains nationwide information on the affiliation to the Fund and from which it must be ensured when assigning the number to the insured person that the reference to the relative who is a member can be established (Section 290 
Part II of the legal opinions: Detailed Questions on organisational and technical measures

para. 1 S. 2 SGB V). The structure and procedure for assigning the health insurance number are regulated in the guidelines of the Central Association of Health Insurance Funds (GKV-SV), Section 290 para. 1 S. 3, Para. 2 S. 1 SGB V.

"To prevent the creation of a personal indicator that is valid across several branches of the social insurance system" 54 the pension insurance number may not be used as a KVNR, but may only be derived retroactively from it. However, it was precisely the purpose of the regulation to "create a permanent identification feature in the telematics infrastructure system" 55 with the unchangeable part of the KVNR.

\subsection{Special legal significance of an unchangeable identifier}

The risk potential of unchangeable personal identifiers lies in the possibility of linking different databases so that comprehensive personal profiles could be created. These considerations are based, inter alia, on the decisions of the Federal Constitutional Court (BVerfG) on the microcensus and the population census. In the microcensus resolution, the BVerfG said:

"It would not be compatible with human dignity if the state could claim the right to compulsorily register and catalog the person in his or her entire personality, even in the anonymity of a statistical survey, and thus treat him or her as a matter that is accessible to an inventory in every respect." ${ }^{6}$

In the census judgment, the BVerfG also stated that a complete or partial registration and cataloguing of the personality was incompatible with human dignity under Article 1 para. 1 of the German Constitution (Grundgesetz-GG). It said, that this may be the case if

“(...) an unrestricted linking of the collected data with the partly very sensitive data stocks available at the administrative authorities or even the indexing of such a data network by a uniform personal identifier or other regulatory feature would be possible; because a comprehensive registration and cataloguing of the personality by the combination of individual life data and personal data for the compilation of personality profiles of the citizens is also inadmissible in the anonymity of statistical surveys." ${ }^{57}$

The introduction of a uniform personal identification mark was therefore "a decisive step towards registering and cataloguing the individual citizen in his

54 BT-Drs. 15/4924, S. 8.

55 Hornung/Roßnagel in: Schneider, Sekundärnutzung klinischer Daten-Rechtliche Rahmenbedingungen, 2015, S. 395.

56 BVerfGE 27, 1 (6).

57 BVerfGE 65, 1 (53). 
or her entire personality" ${ }^{8}$ and, according to this opinion, should be constitutionally inadmissible. ${ }^{59}$ However, as long as serial numbers, e.g. passport or ID card numbers, are only used for one purpose or for manageable purposes, they are considered permissible. ${ }^{60}$ The BVerfC has also not universally and unconditionally rejected the introduction of personal identifiers; a constitutional design would be conceivable through organisational, technical and legal measures. ${ }^{61}$

The problem of a uniform personal identification number is also addressed in Art. $87 \mathrm{GDPR}$. Accordingly, there is an opening clause in favour of the Member States concerning the processing of a national identification number or other marks of general importance. Member States may allow processing by national law, but must provide appropriate safeguards for the rights and freedoms of the data subject. In Germany there are no national identification numbers and the sectoral personal identifiers, such as the KVNR, are not of "general significance" within the meaning of Art. 87 GDPR; they are therefore subject to general data protection law. ${ }^{62}$

\subsection{Additional sensitivity as a Data about health?}

With regard to the KVNR, it could be considered that this is already data concerning health, as recital 35 states:

"Personal data concerning health should include all data pertaining to the health status of a data subject which reveal information relating to the past, current or future physical or mental health status of the data subject.

This includes information about the natural person collected in the course of the registration for, or the provision of, health care services as referred to in Directive 2011/24/ EU of the European Parliament and of the Council (9) to that natural person; a number, symbol or particular assigned to a natural person to uniquely identify the natural person for health purposes; information derived from the testing or examination of a body part or bodily substance, including from genetic data and biological samples; and any information on, for example, a disease, disability, disease risk, medical history, clinical treatment or the physiological or biomedical state of the data

58 BVerfGE 65, 1 (57).

59 Polenz in: Kilian/Heussen, Computerrecht, 33. El Februar 2017, 1. Abschnitt. Erläuterungen Teil 13: Datenschutz Verfassungsrechtliche Grundlagen des Datenschutzes Rn. 18-21

60 Polenz in: Kilian/Heussen, Computerrecht, 33. El Februar 2017, 1. Abschnitt. Erläuterungen Teil 13: Datenschutz Verfassungsrechtliche Grundlagen des Datenschutzes Rn. 20.

61 Martini/Wagner/Wenzel, Rechtliche Grenzen einer Personen- bzw. Unternehmenskennziffer in staatlichen Registern, 2017, S. 62; with the correct remark that the technical possibilities of BigData applications relativize the importance of personal identifiers, since profile formation can also take place on the basis of many different data records. see regarding the tax numbers: FG Köln, Urt. v. 7.7.2010-2 K 2999/08.

62 BeckOK DatenschutzR/ von Lewinski, 23. Ed. 1.2.2018, DS-GVO Art. 87, Rn. 53. 
Part II of the legal opinions: Detailed Questions on organisational and technical measures

subject independent of its source, for example from a physician or other health professional, a hospital, a medical device or an in vitro diagnostic test." [Highlighting not in original text]

Thus, identification markers in themselves would also represent health data, although they do not necessarily provide information about the state of health. However, the meaning of recital 35 is unclear. This extensive understanding of the concept of health data has not been reflected in the text of the Regulation: The wording of Article 4 No. 15 GDPR defines data concerning health on as:

"personal data related to the physical or mental health of a natural person, including the provision of health care services, which reveal information about his or her health status;"

An interpretation according to the solely relevant wording of the standard text as well as an interpretation according to systematics, sense and purpose, however, argues against an extension of the definition of data concerning health to identifying characteristics which do not contain any health-related meaning. We therefore are of the opinion that the processing of the KVRN does not qualify as processing of data concerning health.

\subsection{Non-validated issuing process}

It should be noted that the creation and distribution of the electronic health card is error-prone and the card cannot be securely attributed to a natural person.

The issuance of the eGK is regulated in $₫ 15$ Para. 6 SGB V, according to which the health insurance funds are to counteract the misuse of the card by appropriate measures.

While the law demands, that the eGK must be signed by the insured person, Section 291 Para. 1 S. 4 SGB V, and that it must also bear the photograph of the insured person Section 291 Para. 1 S. 4 SGB V, ${ }^{6}$ it is not expressly regulated in the law how the health insurance funds ensure that the picture provided is actually one that shows the insured person or how the information provided by the insured person, for example within the scope of reporting the data in accordance with $\mathbb{1}$ 10 Para. 6 SGB V, is validated. Likewise, the manner in which the card is issued is not prescribed. In contrast to identity documents such as identity cards or passports, electronic health cards are not issued in a personal handover process, but are sent by mail. Although this procedure is

63 However, an electronic health card without a photograph must be issued for insured persons up to the age of 15 and for those whose participation in the creation of the photograph is not possible (Section 291 Para. 2 S. 5 SGB V). 
not demanded by law as a mandatory procedure, it is considered permissible in any case (cf. Section 291a Para. 3 S. 3 SGB V: "when sending the card”).

The non-validated process was dealt with in a so-called "small inquiry" to the Federal Government. The Federal Government replied that the health insurances are responsible for the issuing process of the eGK and that a sufficient identification of the insured persons would be ensured by the statutory reporting provisions in according to Section 5 Para. 5 Ordinance on the Collection and Transmission of Data for Social Insurance Institutions (Data Collection and Transmission Ordinance-DEÜV) upon entry into the statutory health insurance system. According to this provision, the personal details reported to the social insurance institutions are to be taken from official documents. This obligation on the part of those obliged to register under Section 2 DEÜV, for example the employer, is sufficient for sufficient identification. The Federal Government did not consider further identification to be necessary as the eGK was not an identity document such as a passport or identity card. Such an obligation would not arise from Section 291 SGB V either.

Furthermore, it cannot be assumed that incorrect data will be discovered and corrected during a visit to the physician, as there is no obligation for health care providers to compare the eGK with an identity card. Only obvious errors that can be identified on the basis of the identity data applied to the eCK (photograph, signature, surname, first name, date of birth) are to be checked by GKV-accredited physicians, cf. No. 1.2. of Appendix 1 to $\$ 7$ of Annex 4 a Federal Master Treaty for Medical Practitioners (Bundesmantelvertrag Ärzte-BMV- ̈̈).

\subsection{Special restrictions of use according to the SGB V}

In the past, the use of the health insurance card (KVK) ${ }^{64}$ and the KVNR for research purposes had been argued on the basis of Section 291 SCB V in its version valid until 28.12.2019. ${ }^{65}$ Thus it was argued that the regulation of Section 291 para. 1 sentence 3 SGB V (old version) prescribed a strict purpose limitation of the eGK as well as the KVNR as proof of insurance and means of settlement. The provision read as follows until 28.12.2015:

"With the exception of $\$ 291 a$, it [the health insurance card] may only be used as proof of entitlement to claim benefits within the framework of GKV-accredited physicians and for invoicing with the heal th care providers." ${ }^{66}$ [Addition in brackets was added by the authors]

64 This was the previous version of the eGK.

65 Hornung/Roßnagel, in: Schneider, Sekundärnutzung klinischer Daten-Rechtliche Rahmenbedingungen, 2015, p. 367-404.

66 "Sie darf vorbehaltlich $\$$ 291a nur für den Nachweis der Berechtigung zur Inanspruchnahme von Leistungen im Rahmen der vertragsärztlichen Versorgung sowie für die Abrechnung mit den Leistungserbringern verwendet werden." 
Part II of the legal opinions: Detailed Questions on organisational and technical measures

This regulation was regarded as conclusive and, with reference to a judgment of the Federal Social Court of 1o December 2008, it was then concluded that processing of the KVNR could not be justified by consent either, since recourse to general data protection laws was not possible. ${ }^{67}$ The Federal Social Court had ruled that billing data according to the SGB V may not be passed on by health care providers to private service providers for billing purposes ${ }^{68}$ Furthermore, it was argued that the extended usage possibilities of the eCK according to Section 291a SGB V (old version) were not sufficient, since Section 291a para. 8 SCB V excluded a consent with justifying effect. ${ }^{69}$

By reforming Sections 291 and 291a SGB V as of 29 December 2015, the strict wording "only" was replaced with the following wording:

"It [the eGK] serves as proof of the entitlement to claim benefits within the framework of CKV-accredited physicians (proof of insurance) as well as the settlement with the health care providers." [Addition in brackets was added by the authors]

The wording of the law therefore no longer excludes any other use of the eGK.

In addition, Section 291a Para. 7 S. 3 SGB V includes a provision on health research. This allows the use of the telematics infrastructure cure for purposes of health research under certain conditions. According to the explanatory memorandum, this provision is intended to enable the use of the telematics infrastructure without the use of the eGK. However, the use of the eCK for research purposes is not permitted by this provision.

Regarding the rulings of the Federal Social Court, which was already criticised under the old legal position of the data protection guideline, ${ }^{70}$ now from a substantial change by the validity acquisition of the GDPR might be to be assumed. In relation to the national law, e.g. the SGB V, the GDPR prevails. Only in the context of Article 9 para. 2 lit. a) GDPR the possibility to consent to the processing of data concerning health can be excluded by the member states. The statement of the Federal Social Court, that there is no principle after which one could fall back on the possibilities of giving consent as provided by general data protection law cannot continue to apply under the general data protection right without further ado. In order for the opening clause of Article 9 para. 2 lit. a) GDPR to be used in conformity with EU law, consent would have to be expressly excluded. This is precisely not the case if the possibility to con-

67 Hornung/Roßnagel, in: Schneider, Sekundärnutzung klinischer Daten-Rechtliche Rahmenbedingungen, 2015, p. 400.

68 BSG, Urteil vom 10. Dezember 2008-B 6 KA 37/07 R-, BSGE 102, 134-148, SozR 4-2500 \& 295 Nr. 2.

69 Hornung/Roßnagel, in: Schneider, Sekundärnutzung klinischer Daten-Rechtliche Rahmenbedingungen, 2015, p. 40380.

70 Kircher, Der Schutz personenbezogener Gesundheitsdaten im Gesundheitswesen, 2016, p. 176; Heberlein, SGb 2009, 717; Brisch/Laue, CR 2009, 465; Schneider, VSSR 2009, 381; Leisner, NZS 2010, 129; Kingreen/Temizel, GesR 2010, 225; Kühling/Seidel, GesR 2010, 231; Hauser, KH 2011, 910. 
sent is assumed to be denied from the reverse conclusion that the legislator allowed consent only in those cases where he wanted to consent to happen and therefore wanted consent to be excluded where it was not expressly permitted.

It should be noted, that Section 291a para. 8 SGB V does not allow to demand Access to certain Data on the eGK nor to conclude an agreement on it. Any infringement of this provision may result in the imposition of a fine according to Section 307 Section 1 SGB V. Anyone who, contrary to Section 291a para. 4, s. 1 or para. 5a, s. 1, first half sentence or sentence 2 SGB V, accesses the data mentioned therein may be liable to prosecution according to Section $307 \mathrm{~b}$ SGB V.

\subsection{Conclusion}

The following can be concluded from the above: The eGK and the KVNR are items particularly worthy of protection. However, the lawful processing of the KVNR for the purpose of scientific research is possible. SGB V does not conclusively regulate the use of the eGK and the KVNR and thus prohibit the processing for the purpose of scientific research. The processing of the KVNR could be performed on a legal basis or on the basis of consent, if this is necessary for the purpose of the processing. Additional consent for the KVNR would not be necessary. However, the "general" declaration of consent should indicate that the number is being processed. From a legal perspective, the question arises as to whether the use of KVNR is absolutely necessary. This has to be considered in the light of the non-validated issuing process of the eCK. In addition it is to be noted that with the use of the KVNR as additional date also additional errors can happen. The necessity of processing the KVNR must therefore be accurately assessed and the supporting reasons documented. 